\title{
How to distinguish long-term individual memory representations? A historical and critical journey
}

\author{
Como distinguir representações de memória individuais de longo prazo? Uma \\ jornada histórica e crítica
}

\section{Marina Trakas*}

\begin{abstract}
Memory is not a unitary phenomenon. Even among the group of long-term individual memory representations (known in the literature as declarative memory) there seems to be a distinction between two kinds of memory: memory of personally experienced events (episodic memory) and memory of facts or knowledge about the world (semantic memory). Although this distinction seems very intuitive, it is not so clear in which characteristic or set of interrelated characteristics lies the difference. In this article, I present the different criteria proposed in the philosophical and scientific literature in order to account for this distinction: (1) the vehicle of representation; (2) the grammar of the verb "to remember"; (3) the cause of the memory; (4) the memory content; and (5) the phenomenology of memory representations. Whereas some criteria seem more plausible than others, I show that all of them are problematic and none of them really fulfill their aim. I then briefly outline a different criterion, the affective criterion, which seems a promising line of research to try to understand the grounds of this distinction.

Keywords: Kinds of memory; Declarative memory; Episodic memory; Semantic memory; Autobiographical memory
\end{abstract}

Resumo: A memória não é um fenômeno unitário. Mesmo entre o grupo de representações de memória individuais de longo prazo (conhecidas na literatura como memória declarativa), parece haver uma distinção entre dois tipos de memória: memória de eventos experimentados pessoalmente (memória episódica) e memória de fatos ou conhecimentos sobre o mundo (memória semântica). Embora essa distinção pareça muito intuitiva, não é tão claro em qual característica ou conjunto de características inter-relacionadas reside a diferença. Neste artigo, apresento os diferentes critérios propostos na literatura filosófica e científica para dar conta dessa distinção: (1) o veículo de representação; (2) a gramática do verbo "lembrar"; (3) a causa da memória; (4) o conteúdo da memória; e (5) a fenomenologia das representações da memória. Embora alguns critérios pareçam mais plausíveis que outros, mostro que todos são problemáticos e nenhum deles realmente cumpre seu objetivo. Em seguida, descrevo brevemente um critério diferente, o critério afetivo, que parece uma linha de pesquisa promissora para tentar entender os fundamentos dessa distinção.

Palavras-chave: Tipos de memória; Memória declarativa; Memória episódica; Memória semântica; Memória autobiográfica

\footnotetext{
Postdoctoral researcher at Conicet (Consejo Nacional de Investigaciones Científicas y Técnicas), Buenos Aires, Argentina. E-mail: marinatrakas@gmail.com
} 
Nowadays, it is a quite accepted fact that all phenomena that are in general labeled as memory cases are in fact extremely heterogeneous. Memory is more an umbrella term than a unitary phenomenon. Individual memories have been distinguished from group or collective memories (some authors have even denied that collective memory is a real memory phenomenon); long-term memories have been also distinguished from short-term memories, and procedural memories from declarative memories (habits and motor skills). Even inside this last group, which refer to long-term individual memories representations that inform action and decision making, a famous distinction has been introduced in the literature a couple of decades ago: memory of experiences-called in general episodic memory-has been opposed to memory of facts-semantic memory-which actually refers to general knowledge about the world. This distinction, outlined first in philosophy and supported by empirical evidence since the 70's, is in fact quite intuitive. Memories of objective and depersonalized information that we have acquired indirectly, through testimonial sources, such as remembering that the capital of the province of Buenos Aires is La Plata, do not seem comparable to the memory of first-hand personal experiences that are colored with subjectivity. Many of these personal memories present a phenomenal richness that impersonal and semantic memories lack, such as a high degree of affect and the presence of visual images. On the other hand, sometimes this dissimilarity shrinks: some personal experiences are so distant in time that one remembers them devoid of all subjectivity, as if they were factual knowledge and did not imply any feeling of reliving or traveling back in time. Sometimes we remember specific moments of our lives that are very vivid, but other times, all that is left from a period of our life is a general impression and we are unable to retrieve any specific event. Sometimes we remember through language, and other times visual images of past events pop into our minds, even when we remember general knowledge about the world.

The reason for distinguishing different categories is -if not to identify natural kinds - at least to make distinctions that are conceptually or empirically useful in order to think about and analyze mental phenomena. As Boyd ${ }^{1}$ and Machery ${ }^{2}$ have pointed out, entities should be clustered together when they share a large set of properties because of some uniform causal mechanism and when these clusters optimize the inductive and explanatory purposes of theories that make reference to them. Although there seems to be an essential difference between memories of experiences and memory of facts in order to justify the distinction in terms of different (natural) kinds, it is not so clear in which characteristic or set of interrelated characteristics lies this difference. If the difference lies in the content, the notions of "experience" and "fact" would need further specification. But the distinction could also be justified through other main characteristic, such as their

\footnotetext{
${ }^{1}$ BOYD, Homeostasis, species and higher taxa.

${ }^{2}$ MACHERY, Doing Without Concepts.
} 
vehicles of representation, their causes, or their different phenomenology. Even if the difference in kind is grounded in the existence of distinct memory systems, different characteristics at the personal level must supervene from these different neural realizations. So the problem of identifying the property or interrelation of properties that establish a distinction between different kinds of long-term individual memory representations still persists.

Through history, philosophers and cognitive scientists have proposed different criteria to account for this intuitive distinction between memories of experiences and memories of facts. In some cases, the criterion proposed leads to make further distinctions between long-term individual memory representations. In this article, my aim is thus to present the different criteria that have been proposed in the literature to distinguish different kinds of long-term individual memory representations, and evaluate if they successfully fulfill their aim. I distinguish five types of criteria according to (1) the vehicle of representation; (2) the grammar of the verb "to remember"; (3) the cause of the memory; (4) the memory content; and (5) the phenomenology of memory representations. As this analysis shows, whereas some criteria are more plausible than others from a theoretical and experimental perspective, none of them is exempt of problems. The major inconvenient seems to be focused on a poor analysis of the interaction and correlation between different significant properties of our memory experiences. At the end of this article, in section (6), I briefly outline a different criterion, the affective criterion, which is promising for accounting for this correlation and may thus in the future, with further research, prove to be more successful than the others to elucidate the diversity of our longterm individual memory representations.

One important remark: as I have already suggested, this analysis is confined to long-term individual memory representations and thus, excludes criteria that contrast these memory representations with something else, such as short-term representations, procedures, habits and motor skills, or collective memories. Therefore, the aim of this work is to set out and critically analyze the variety of criteria present in the literature to distinguish different kinds of long-term individual memory representations.

\section{The grammatical criterion}

The grammatical criterion-a criterion based on the grammar of the verb "to remember"-is in certain way the most superficial criterion to distinguish different longterm individual memory representations. The distinction between different kinds of memories according to the grammatical objects of the verb to remember has its origins in the distinction between memories of facts and memories of experiences that was object of philosophical debate during the 60's and 70's. 
Factual memory is unanimously considered to refer to memories whose natural expression involves a clause of the form "remember that p" where $\mathrm{p}$ stands for a proposition which has the property of being true or false $\mathrm{e}^{3}$. But factual memory, according to the grammatical distinction, is not limited to general knowledge, such as "I remember that Paris is the capital of France". It can also refer to personal events. When it refers to personal events, it would be the equivalent of remembering not the past experience, but that something personally experienced occurred or existed, as in the following example: "I remember that I went with my family to Barcelona for the Easter holidays". Event memory, on the contrary, which has also been named "personal memory" or "experiential memory", is characterized by the gerundival construction in -ing: I remember verb +- -ing $^{4}$, as in "I remember reading your book" or "I remember the sun going down over the Indian Ocean". Other authors consider that nominalizations of verbs are also possible objects of event memories, as in "I remember the hike through the Berkshires" 5

This is the most common way in which grammar has been used as a criterion to distinguish two different kinds of memory. Nonetheless, more recently, Bernecker ${ }^{6}$ broadened and reformulated this dual distinction in order to add new memory categories. According to his grammatical taxonomy, propositional memory refers to "any 'substituent' of the schema 'S remembers that p', irrespective of whether 'p' refers to something one has personally experienced"7 or not. In addition, propositional memory can also take the form of "wh-clauses”, such as “I remember 'who', 'whom', 'what', 'where', 'when' or 'why”". These cases of extroversive propositional memories contrast with cases of introversive propositional memories, which refer to one's own mental states, are necessarily in the first-person mode and contain a second-order subordinated proposition with a verb in a past tense: "I remember that I [remembered, thought, believed, inferred, etc.] that p". Nonpropositional memory, on the other hand, not only refers to event-memory (I remember verb + ing), but also to object-memory (I remember + noun) and property-memory (I remember + noun + of noun). To conclude, in Bernecker's taxonomy the grammatical criterion is completely detached and independent of the content one: it is the sole syntactic form that determines the nature of a memory.

Nonetheless, the grammatical criterion does not constitute a good criterion to distinguish memory kinds because it merely provides just that: a grammatical distinction, while pretending to provide something more than a grammatical distinction, such as a distinction of psychological memory kinds. First, the grammatical criterion on one hand divides memories that seem to have more properties in common and could be explained by

\footnotetext{
${ }^{3}$ MALCOLM, Knowledge and Certainty. BERNECKER, Memory: A philosophical Study.

${ }^{4}$ WOLLHEIM, The Thread of Life. BERNECKER, Memory: A philosophical Study.

${ }^{5}$ MALCOLM, Knowledge and Certainty, p. 215.

${ }^{6}$ BERNECKER, The Metaphysics of Memory; Memory: A philosophical Study.

${ }^{7}$ BERNECKER, Memory: A philosophical Study, p. 20.
} 
the same causal mechanism, such as "I remember that I read your book" and "I remember reading your book", both of which refer to a past event experienced by the rememberer, and on the other hand clusters together memories that do not share many properties, such as "I remember that I read your book" (that + event experienced) and "I remember that Paris is the capital of France" (that + fact or semantic knowledge). This suggests that the grammatical criterion is exclusively based on syntax and does not even consider semantics, which would be essential to the understanding of memory, even from a grammatical point of view. Second, this syntactic distinction is not even a good syntactic distinction: it is exclusively based on the analysis of English and does not consider the fact that some other languages, such as Japanese, do not have the same kind of gerundival constructions ${ }^{8}$. But the essential problem is that the grammatical criterion is intended to be more than just a syntactic and semantic distinction; it presumes to assert a difference at the psychological level, in the sense that it aims to explain different ways in which we can remember and not different syntactic constructions of the verb "to remember". Maybe the grammatical criterion was thought by some authors as a simple way of using different terms to express different kinds of memories based on another criterion, such as the content criterion. "Remembering that p" would express memories of facts or knowledge whereas "remembering + ing", memory of experiences. If it is the case, the grammatical distinction should get stuck to its origins and be simply used as a way of naming different memories in English, but it should not be considered as an independent criterion to distinguish different kinds of memories.

\section{The vehicle criterion}

By vehicle, I refer to the more known notion of vehicle of representation or mean of representation in opposition to the notion of representational content. The vehicle criterion is the oldest criterion to distinguish between different memory kinds that can be found in the literature. Although there are some references to this distinction in Plato's writings, it is Aristotle who first made it explicit in De Memoria et reminiscentia. In this text, Aristotle distinguishes between memory (mneme) and recollection (anamnesis). Aristotle considers that memory has a particular affinity with imagination (phantasmata). Memory is an affection (pathos), and imprinted trace, and thus refers to the capacity of "having" images that correspond to previous sense perception, knowledge or judgment. Recollection, on the other hand, is an organized search, and thus, it presupposes an orderly method, usually called association of ideas: the rememberer has to move through a series of images that follow an order in a particular succession. It may be interpreted that for Aristotle "memory is nonpropositional and is similar to scenic memory", whereas

\footnotetext{
${ }^{8}$ For a detailed analysis of the language of memory see: AMBERBER, The Language of Memory in a
} Crosslinguistic Perspective. 
"recollection is propositional and is similar to narrative memory"9. Although Aristotle's distinction between two kinds of memory: mneme and anamnesis, is not solely built on the mean of representation, but also in the underlying processes: passive versus active, involuntary versus voluntary, it is generally taken as an example of a distinction based on the vehicles of representation especially because of its influence during the Antiquity and the Middle Ages. Cicero, Plotinus, Augustine, Avicenna, Averroes, Albert the Great, Thomas Aquinas, mostly all philosophers after Aristotle adopted the dichotomy between a sensible memory that would be a kind of mental picture that reduplicates in the mind past perceptual and sensory experiences, and an intellectual memory, a recollection of ideas that is presented discursively as an argument or speech.

This first distinction between visual memories and propositional memories does not really parallel the intuitive distinction between memory of experiences and memory of events. Nonetheless, someone could think that memories of experiences are imagistic and memories of facts are propositional. Michaelian ${ }^{10}$ does not propose a specific account on the topic, but mentions in his book ${ }^{11}$ that semantic memories have propositional content, whereas episodic memories consist primarily of imagistic content (although it may also include propositional content). Whereas visual and spatial imagistic contents may be considered to be essential to episodic memory-such as Rubin ${ }^{12}$ has defended-, spatial and visual imagery is certainly not sufficient to distinguish episodic from semantic memory. Semantic knowledge or memories of impersonal information of the world, such as "The Amazon is currently burning at a record rate", can also been retrieved through more than just propositional vehicles: they can be constructed from different pieces of information that come in different formats. For example, this memory can come with visual images of the forest burning I saw on TV, of a map of Brazil or South America, etc. The emotion system can also intervene in the retrieval of semantic memories: I can remember the current Amazon rainforest fires with rage or sadness (although in this case these emotions are not really part of the memory but show the way these memories are appraised). On the other hand, although impairments of visual imagery have been associated with amnesia ${ }^{13}$, visual and spatial imagery may not be really necessary to episodically remember: blind people certainly remember, mainly through auditory imagery and narrative forms ${ }^{14}$. In conclusion, episodic memories probably present a richer imagery than semantic ones, but the presence of mental images, or of any other vehicle of representation, is not in itself sufficient to make a distinction between different kinds of

\footnotetext{
${ }_{9}^{9}$ NIKULIN, Memory in Ancient Philosophy, p. 69.

${ }^{10}$ MICHAELIAN, Mental Time Travel: episodic memory and our knowledge of the personal past.

${ }^{11}$ Idem, p. 35, p. 53.

${ }^{12}$ RUBIN, Event memory: A theory of memory for laboratory, autobiographical and fictional events.

${ }^{13}$ GREENBERG; RUBIN, The neuropsychology of autobiographical memory.

${ }^{14}$ TEKCAN et al., Retrieval and phenomenology of autobiographical memories in blind individuals.
} 
long-term individual memory representations, and may not even be necessary to characterize the particularity of one kind of memory representation such as memory of events personally experienced.

In fact, many authors have proposed that there is a single vehicle for all long-term individual memory representations, such as Bartlett ${ }^{15}$ and Russell ${ }^{16}$, who considered that genuine and pure memories are pictures of past occurrences, that is, memory-images. But more recently conceptualizations of episodic memory have highlighted quite the opposite characteristic: episodic memory is constructed from information carried by different vehicles. Probably the first proponent of this conception was Paivio, who in the 1970's reintroduced the notion of images as a particular kind of representation different from the linguistic one. He postulated the dual code theory of memory, which considers that visual and verbal information are encoded in two systems that interact but are functionally independent ${ }^{17}$. Rubin ${ }^{18}$ also proposed a multimodal and multi-system model of episodic memory. According to his model, different aspects of episodic memories are stored not in an abstract format but in different systems, that is why episodic memories are always formed by the mutual coordination of independent systems. These basic systems are independent because each one uses different structures and processes for fundamentally different kinds of information. Each one has also its own functions, neural substrates and types of errors that affect memory. These basic memory systems that provide different kinds of information are generally coordinated by the explicit memory system and the search and retrieval system, both of which are considered as the behavioral and neural basis of episodic memory. So according to Rubin, the main system of episodic memory does not encode specific information but coordinates information coming from systems that are not memory-specific. Concerning these basic systems that are not memoryspecific, Rubin distinguishes different sensory systems, the language and narrative systems and the emotion system. In relation to the sensory systems, he considers that each one provides different kinds of information to the episodic memory: "different senses process information about different properties of the environment (e.g. electromagnetic radiation, vibration, pressure, chemicals that contact the sensory surface), using different transducer mechanisms and neural networks that have different short- and long-term relevance to different aspects of the individual's behavior"19. Visual, spatial, olfactory, auditory, gustatory and tactile forms of imagery not only rely at the subpersonal level on different systems but also present specific properties and characteristics at the personal level that make them different from each other as well as from other different kinds of

\footnotetext{
${ }^{15}$ BARTLETT, Remembering.

${ }^{16}$ RUSSELL, The Problems of Philosophy.

${ }^{17}$ PAIVIO, Mental Representations.

${ }^{18}$ RUBIN, The basic-systems model of episodic memory.

${ }^{19}$ Idem, p. 282.
} 
representations, like linguistic ones. In fact, according to Rubin empirical studies are consistent with the idea that visual and multimodal objects and scenes are stored both in the original sensory systems and in the language system, more specifically, in the language that has been used at the time of the event ${ }^{20}$.

Nonetheless, the idea that memories are constructed from different bits of information coming from different systems does not entail that the sources of these different kinds of information are exclusively memory systems. As a matter of fact, these different bits of information not only contribute to the construction of memories but also to the construction of imaginative scenarios and fictitious experiences, and the simulation of future episodes. Consider the visual and spatial system. Research has shown that the generation, maintenance, and visualization of complex spatial contexts, that is, the process of scene construction, is a common process underlying episodic memory and imagination ${ }^{21}$. Patients with long-term visual memory loss cannot draw objects or describe property objects from memory or have a visual image of objects upon introspection ${ }^{22}$. But like blind people, they can certainly remember experiences from their past, as well as other impersonal information about the world, in a linguistic or other kind of sensory form. Therefore, these bits of visual and spatial information that have been encoded in the visual and spatial system are not per se different kinds of memories but just different kinds of information that contribute to the construction of different kinds of mental states, such as memories, fictional imaginings, future self-projection, navigation, etc. The same could be said about the other systems, such as the emotion system, which can also intervene in current perceptions, perceptions of fiction (watching a movie, reading a novel), imaginings, future simulation, memories, just to give some examples.

In conclusion, the vehicle criterion does not constitute a good criterion neither to characterize memory nor to distinguish different memory kinds. If the vehicle criterion was employed as a criterion to distinguish different kinds of memories, it would be too broad and inclusive and would not only include other mental states and experiences that are not past-oriented and have a completely different nature (imaginings, simulations, perceptions, etc.), but would not even do its job of distinguishing different long-term individual memory representations. That is why it is better to consider the vehicle criterion as a criterion to distinguish different kinds of information that are used by different mental capacities, such as imagination, future projection, navigation, etc., as well as in the construction of different kinds of memories, such as memories of episodes personally experienced in the past and memories of impersonal information about the world.

20 SCHRAUF, Bilingual autobiographical memory: Experimental studies and clinical cases. MARIAN; NEISSER, Language-dependent recall of autobiographical memories.

${ }^{21}$ HASSABIS et al., Using imagination to understand the neural basis of episodic memory.

${ }^{22}$ FARAH, The neurological basis of mental imagery: A componential analysis. 


\section{The causal criterion}

The causal criterion to distinguish memories is based on the previous condition that is necessary to remember a past event, and also appears in relation to the philosophical distinction between memory of facts and memory of events, as I show below.

Although the causal criterion may be at first sight associated to the causal theory of memory, the major proponents of this theory ${ }^{23}$ did not use it to establish a distinction between different kinds of long-term individual memory representations. Bernecker adopted a grammatical criterion to make distinctions and applied the causal theory to all cases of propositional memory. Concerning Martin \& Deutscher, while at the beginning of their seminal paper, they suggest that there are memories that require a previous experience of what is remembered and other that do not, they finally analyzed both of them within the same causal framework. In fact, a memory of some information gained through testimony does not imply a direct experience of the event remembered but it does imply a previous (and direct) experience of learning about that event through visual or auditory perception. Because the causal condition comprehends memory of events, general knowledge, and even procedural memories ${ }^{24}$, it is not useful per se to establish distinctions between different kinds of memories.

This conclusion can be questioned if memories are produced by causes that are different in nature. Different causes produce in principle different memory phenomena. Some authors have proposed that memory of events only requires as a previous condition that the remembered event is based on a previous experience or perception of that event, whereas knowledge or factual memory requires that the present knowledge or belief about a past event is based on a past knowledge or belief. The introduction of the notions of "knowledge" and "belief" refines the characterization of the kind of "experience" that is necessary to remember events learnt through testimonial sources (understood in a broad sense) in opposition to events that have been directly experienced by the rememberer (realization, participation or direct perception). Malcolm ${ }^{25}$ is an advocate of the strong sense of this criterion. He defines event memory or personal memory in the following terms: “A person $\mathrm{B}$ personally remembers something, $\mathrm{x}$, if and only if $\mathrm{B}$ previously perceived or experienced $\mathrm{x}$ and B's memory of $\mathrm{x}$ is based wholly or partly on his previous perception or experience of $\mathrm{x}$ "26, whereas factual memory is defined as "A person $\mathrm{B}$ remembers that $\mathrm{p}$ if and only if $\mathrm{B}$ knows that $\mathrm{p}$ because he knew that $\mathrm{p}^{27}$. Fernandez ${ }^{28}$, on

\footnotetext{
${ }^{23}$ MARTIN; DEUTSCHER, Remembering. BERNECKER, Memory: A Philosophical Study.

${ }^{24}$ MICHAELIAN, Opening the doors of memory: is declarative memory a natural kind?

${ }^{25}$ MALCOLM, Knowledge and Certainty.

${ }^{26}$ Idem, p. 215.

${ }^{27}$ Idem, p. 223
} 
the other hand, defends a weaker version: whereas factual memory of the proposition $\mathrm{p}$ requires previous belief that $\mathrm{p}$, event memory of $\mathrm{p}$ is possible even if the rememberer had never believed that $\mathrm{p}$ before. Despite this distinction, Malcolm ${ }^{29}$ for example has admitted the existence of some relation between these two kinds of memories. According to him, personal memory entails a factual memory version of itself: "A person who personally remembers the burning of the city hall could be said, in this derivative sense, to personally remember that it burned" 30 . He named this memory personal factual memory in opposition to non-personal factual memory. Here we have two possible interpretations: either Malcolm considers that when we lose the capacity to bring back details of a past experience the personal memory becomes a factual memory, or he believes that while experiencing an event we always gain and form some knowledge, which is in certain way encoded independently of the experience itself and can be later recalled in the form of personal facts.

In any case, the causal criterion implies epistemological assumptions about the way in which our memories are justified: factual memories always require a prior belief, if not knowledge. This thesis corresponds to the epistemic theory of memory. I will nonetheless avoid a deep analysis of the epistemic theory of memory and just focus on the two formulations mentioned earlier. For my purposes the only question that matters is if the criterion is useful to distinguish between different kinds of long-term individual memory representations. It has been criticized ${ }^{31}$ that factual memory is an umbrella category that includes two different kinds of memories, i.e. memory of events personally experienced and memory of events learned through testimony ${ }^{32}$. This criticism could be overcome if we take into consideration the distinction made by Malcolm between personal and nonpersonal factual memories. Nonetheless, this distinction would cluster together factual memory and personal factual memories, which are memories that have little in common except the fact of being caused by a past belief / knowledge, and would divide personal memories in two different kinds for the only reason of being produced or not by a past belief / knowledge. Furthermore, the most important criticism points to the fact that a previous belief or knowledge is neither sufficient nor necessary for having a factual memory. First, remembering-even factually remembering-cannot be equated with knowing that or believing that. Cases of relearning, in which a subject knows or believes that $\mathrm{p}$ at time $\mathrm{t} 1$, then forgets $\mathrm{p}$ at time $\mathrm{t} 2$, and then relearns $\mathrm{p}$ again at time $\mathrm{t} 3$, prove that

\footnotetext{
${ }^{28}$ FERNANDEZ, The Intentionality of Memory.

${ }^{29}$ MALCOLM, Knowledge and Certainty.

${ }^{30}$ Idem, p. 216.

31 MUNSAT, The Concept of Memory. SAUNDERS, Does all memory imply factual memory?. NAYLOR, Remembering-that: episodic vs. semantic.

${ }^{32}$ MUNSAT, The Concept of Memory.
} 
someone can know or believe that $\mathrm{p}$ without for that remembering that $\mathrm{p}^{33}$. This example shows that previous knowledge or belief is not sufficient for factual memory and that factual memory cannot be equated to present belief or knowledge. Secondly, previous knowledge and belief are not even necessary to remember something. Cases of inattentive remembering, that is, when we are inattentive and do not form a conscious belief while experiencing the event but we form it later while remembering the event ${ }^{34}$, or cases when we do not consciously form a belief about $\mathrm{p}$ but then a defeater of $\mathrm{p}$ is removed and thus we remember $\mathrm{p}^{35}$, or negative memories, like remembering not having done something, are common counterexamples that have been used in the literature to argue that past knowledge and beliefs need not be a necessary requirement to remember beliefs or past experiences ${ }^{36}$. Therefore, previous knowledge or belief cannot be a criterion to identify different kinds of memory: not all current beliefs and knowledge are memories, and memories do not require previous knowledge and beliefs.

In consequence, it seems that the causal criterion that distinguishes different kinds of memory in function of their cause: previous perception/first-hand experience for event memory versus previous knowledge $e^{37}$ or previous belief ${ }^{38}$ for factual memory, does not really constitute a good criterion to discriminate what it pretends to discern: memory of personal experiences and memories of information acquired through testimony.

However, there is another possibility to establish different kinds of memories based on the cause. Instead of focusing on the distal cause of memories, a distinction can be made in relation to their proximate cause: the memory trace. Memories of events personally experienced could be caused by different memory traces than factual memories. This is the proposal done by Chen $\&$ al. who consider that the episodic memory trace is one of the key elements that enables the construction of episodic memories. Episodic memory traces refer to information stored in the brain about the gist of one specific experienced event, and contrasts with traces that refer to information of "multiple, personally experienced or not, episodes (semantic information)" ${ }^{39}$. Nonetheless, Chen \& al. admits that through repeated reactivation in the construction of episodic memories, episodic traces can in certain way become semantic ${ }^{40}$, and they even acknowledge that "there may be no clear line that divides episodic memory traces from semantic information, since some cases cannot be easily recognized as either one or the other,

\footnotetext{
${ }^{33}$ MARGOLIS, Remembering. MUNSAT, The Concept of Memory.

${ }^{34}$ LACKEY, Memory as a Generative Epistemic Source.

${ }^{35}$ NAYLOR, Remembering-that: episodic vs. semantic.

${ }^{36}$ For a general review of these arguments, see BERNECKER, Memory: A Philosophical Study.

${ }^{37}$ MALCOLM, Knowledge and Certainty.

${ }^{38}$ FERNANDEZ, The Intentionality of Memory.

${ }^{39}$ CHEN et al., Dissociating memory traces and scenario construction in mental time travel, p. 8.

${ }^{40}$ Idem, p. 12.
} 
leaving the possibility that the two are different by degree rather than by kind" 41 . Chen \& al.'s model of episodic memory is more complex than that (it is not only based on a memory trace), and a real criticism lies outside the scope of this article. But it is worth it to mention that an episodic memory trace is not sufficient to make a distinction between different kinds of memories. As I will better develop on the section about the content criterion, first, it is not clear how specific must be the event from which the episodic memory trace derives. And second, in some cases semantic information can be tied to a memory trace of a quite specific and single episode, such as when I remember an event I have not first-hand experienced but that I have recently heard about on the news. I can even forget the context in which I learnt that information, without this implying that the memory retrieved is not caused by a single and near-experience memory trace. Acquisition of semantic information may depend on the acquisition of the episode of which they are a part ${ }^{42}$, and thus episodic memory traces may also be involved in the retrieval of semantic information about the world.

Tulving's serial-parallel-independent (SPI) model of memory also considers that there are different memory traces that are at the origin of different memory representations. According to the serial-parallel-independent model, information about an event is processed and encoded first in semantic memory and then in episodic memory, stored in parallel in both systems and retrieved independently. Unlike Chen \& al., the difference does not reside on the level of generality of the information carried by the trace, but on the nature of the information encoded, which is determined by the nature of the original information processed and the property of the system in question ${ }^{43}$. So for Tulving there is no single trace or single engram for an event (even for an experience-near event), but "different kinds of information, representing the many different aspects of the event, are stored at different independent storage sites" ${ }^{44}$. For example, the semantic memory system can process and encode the concepts in relation with their meaning; its output reaches then the episodic memory system, which "computes the temporal-spatialcontextual coordinates of the incoming information in relation to already existing episodic information, or to the self" ${ }^{45}$. Nonetheless, it is not really clear what are the particularities of each kind of information, especially of the information carried by the semantic memory trace. On the other hand, if the episodic memory trace refers to the temporal-spatialcontextual information of an event, it faces significant challenges, as it will be shown in the following section. What is more, the SPI model has received criticism from some

\footnotetext{
${ }^{41}$ Idem, p. 9

42 NADEL; MASCOVITCH, Memory Consolidation, Retrograde Amnesia and the Hippocampal Complex; SQUIRE; ZOLA, Episodic memory, semantic memory, and amnesia.

${ }^{43}$ TULVING, Organization of memory: Quo vadis?

${ }^{44}$ TULVING, Study of memory: processes and systems, p. 20.

${ }^{45}$ TULVING, Organization of memory: Quo vadis?, p. 844.
} 
authors who questioned the idea that information can only be processed and encoded in episodic memory via semantic memory ${ }^{46}$.

But independently of the more technical problems related with the SPI model, and more broadly with the episodic memory trace, it is possible to conceive that what causes different long-term individual memory representations is the existence of different memory systems. Memory systems are defined by Tulving as "organized structures of more elementary operating components. An operating component of a system consists of a neural substrate and its behavioral and cognitive correlates. Some components are shared by all systems, others are shared only by some, and still others are unique to individual systems" ${ }^{47}$. This means that episodic memory is an independent memory system that differs from other memory systems such as the semantic memory system in the information it processes, the laws and principles of its operations, its behavioral and cognitive functions but also its neural substrates and mechanisms ${ }^{48}$. The notion of multiple memory systems is in general widely accepted ${ }^{49}$. Although it has been questioned by researchers who defend the idea that episodic and semantic memory can be distinguished focusing on processes and not on systems ${ }^{50}$, Tulving ${ }^{51}$ has denied the existence of an opposition between memory systems and memory processes or mechanisms and has advocated for a complementarity of approaches (specially through the development of his SPI model). The discussion of the problems surrounding the notions of memory systems and memory processes are beyond the scope of this article. But the point I would like to highlight is that establishing different neural memory systems does not solve the problem of distinguishing different kinds of long-term individual memory representations: more needs to be said about the main operational and computational characteristics that accompany different neural substrates, that is, about those "components (...) that are unique to individual systems".

In fact, Tulving was not foreign to this concern: his own definition of system is not reduced to a neural system but encompasses different operating components. Although in some writings he suggested that there are a large number of characteristics that distinguish episodic from semantic memory without specifying which ones are the main ones, in other writings he suggests quite the opposite: the content of memories, and in later reformulations their phenomenology, are presented as the defining traits of each kind

\footnotetext{
${ }^{46}$ GRAHAM et al. Insights from semantic dementia on the relationship between episodic and semantic memory.

47 TULVING, Memory and consciousness, p. 387.

${ }^{48}$ Idem.

${ }^{49}$ SQUIRE, Memory systems: A biological concept.

${ }^{50}$ E.g. BLAXTON, Investigating dissociations among memory measures. ROEDIGER; McDERMOTT, Implicit memory in normal human subjects. CABEZA; MOSCOVITCH, Memory systems, processing modes, and components.

${ }^{51}$ TULVING, Study of memory: processes and systems.
} 
of long-term individual memory representation. In the next two sections, I explore these two main characteristics that, as I show, are not exempt of problems.

\section{The content criterion}

The content criterion-a criterion based on the intentional object of the memory-is probably the more intuitive criterion to establish different long-term individual memory representations. This classic criterion has been widely used in philosophy: many philosophers from the beginning of the 20th century have distinguished between memory of events personally experienced (event-memory, personal memory or experiential memory) and memory of facts (factual memory). As it has been explained in a previous section, some philosophers founded this distinction on the grammar, and thus any memory of the form 'I remember that p' was considered as a factual memory. But for other philosophers, the difference is exclusively based on the content, that is, on the intentional object of the memory: whereas event-memory refers to memory of events personally experienced by the rememberer, factual memory refers to memory of abstract and impersonal information about the world that has been acquired through testimony.

Nevertheless, it was probably in the psychological field that the distinction between these two kinds of memory was better characterized. Although Tulving is not the author of the notions of "episodic memory" and "semantic memory", it was the first who presented them together as different and opposite kinds of declarative memory.

Originally, Tulving developed the difference between the content of these two memories by specifying the kind of information encoded by these two different systems. Whereas semantic memory retains information about the meaning of words and concepts and their interrelations, episodic memory retains "information about temporally dated episodes or events and temporal-spatial relation among these events" ${ }^{52}$. So three kinds of information are retained in episodic memory: the what, where and when of some particular event that happened in the past. That is why this kind of memory has been called $w w w$ memory by Clayton \& Dickinson ${ }^{53}$. Whereas the where and when would correspond to the setting of an event, the what, that is, the salient happening within the setting would correspond to the focal element of the event ${ }^{54}$. Because it is the contextual information of the event which is essential to episodic memory (when semantic memory encoded interrelations between concepts, it also encodes the "what" of an event) this first characterization of episodic memory has been considered as a contextual description ${ }^{55}$. As McCormack explained "the general idea is that whereas factual memory simply involves

\footnotetext{
${ }^{52}$ Idem, p. 385.

${ }^{53}$ CLAYTON; DICKINSON, Episodic-like memory during cache recovery by scrub jays.

${ }^{54}$ TULVING, Elements of Episodic Memory, p. 143.

${ }^{55}$ McCORMACK, Attributing episodic memory to animals and children.
} 
retrieval of the fact acquired during a given learning episode, the corresponding episodic memory would involve remembering something about the specific learning episode itself, namely the context in which the fact was acquired" ${ }^{56}$. If this criterion seems, in principle, adequate to specify the characteristics that distinguish memories of events personally experienced from memories of facts about the world, and it also accommodates some empirical data, it does not actually constitute a good criterion to distinguish different kinds of long-term individual memory representations.

First, Tulving suggests that contextual information is stored with event information in memory but he neither explained how, nor in what consists this specific relevant contextual information. In fact, this last assumption presents some difficulties that have been expressed by $\mathrm{McCormack}^{57}$. First, we are often able to correctly recall perceptual properties of events without accurately recalling the temporal and contextual information. Second, we are able to recall temporal and contextual information of events not personally experienced; and finally, we are able to make temporal and contextual judgments based on ways different from the retrieval of stored pieces of contextual information. All these criticisms point to the fact that temporal and contextual information is neither necessary nor sufficient to define the episodic character of a memory. As McCormack wrote, "if it is argued that the temporal-contextual information is often not accessible for retrieval, it is not clear what is useful about introducing this type of information to do the job of ensuring the specificity of episodic memories" ${ }^{58}$. If we do not ensure the specificity of episodic memory, there is no possible distinction between two kinds of memory.

Second, Tulving establishes that episodic memories are memories of occurrences of an episode, that is, "an event that is distinctive and separate although part of a larger series" 59 that happens in a particular place at a particular time. It has a beginning and an end and the interval is filled with some action which involves the rememberer, either as an actor or as an observer ${ }^{60}$. This suggests that the notion of 'event' corresponds to a quite minimal and short time slice of experience and, thus for example, the memory of some holiday trip would be too broad to be considered as an episodic memory but will not fit either as a case of semantic memory which is conceived as "culturally- shared general knowledge (including facts and vocabulary)" and is characterized by being "detached from its context of acquisition and devoid of any subjective sense of mental time travel" 61 . This leaves the memories of personal general events in a sort of conceptual limbo: they do not

\footnotetext{
${ }^{56}$ Idem, p. 286.

${ }^{57}$ Idem, p. 293, 294.

${ }^{58}$ Idem, p. 295.

59 TULVING, Episodic and semantic memory, p. 385.

60 TULVING, Elements of Episodic Memory, p. 37.

${ }^{61}$ RENOULT et al. Personal semantics: at the crossroads of semantic and episodic memory, p. 550.
} 
actually meet the criteria to be considered neither cases of semantic memories nor episodic memories.

Finally, as I have anticipated in the section about the causal criterion, there is the problem of the specificity of the event of an episodic memory. The idea that the event remembered must be experience-near to count as an episodic memory certainly dismisses general and very abstract events as possible objects of episodic memories, but it does not clarify how much "experience-near" the event should be in order to be an object of episodic memory. Given that an event can always be divided into other more particular events, the memory of meeting someone for the first time, for example, (which can be decomposed into looking into each other's eyes, saying "Hi", shaking hands, introducing themselves) could be considered as too general to count as a real instance of episodic memory, but probably nobody would agree in denying the episodic status to this kind of memory.

The concept of autobiographical memory appeared in certain way to fill up this void by proposing that memories of our personal past have different levels of abstraction and generality, are hierarchically organized in a nested structure, and are not necessarily episodic in nature. Because this concept proposes a richer characterization of memories of our personal past than the sole notion of episodic memory, it presents a solution to the problem of the conceptual limbo of memories of not experience-near events which is characteristic of Tulving's dichotomical model, while avoiding the first problem: autobiographical memories are not defined in function of their location in space and time but according to the level of abstraction of the event remembered.

Different computational and psychological models of autobiographical memories were developed from the 80 's by Kolodner ${ }^{62}$, Linton ${ }^{63}$, and Barsalou ${ }^{64}$, among others. But probably Conway's ${ }^{65}$ model is the most known because of its several reformulations. Although each model presents its own characteristics and particularities (which I cannot develop here), all of them recognize the existence of different levels of abstraction of events that can go from those that are experience-near to those that are highly abstract and involve a period of our lives. That is why when remembering events of our personal past, the content of our memories can be a simple event: opening the car to go to the airport; a complex event: driving to go the airport; a general event, that includes repeated events: weekends at the beach, and single general events: trip to Malaysia; an extendure: living in the white house in Newtown; or an entire life-time period: our childhood.

\footnotetext{
${ }^{62}$ KOLODNER, Maintening organization in a dynamic long-term memory; Retrieval and Organizational Strategies in Conceptual Memory: A Computer Model.

${ }^{63}$ LINTON, Ways of searching and the contents of memory.

${ }^{64}$ BARSALOU, The content and organization of autobiographical memories.

${ }^{65}$ CONWAY, A structural model of autobiographical memory; Autobiographical knowledge and autobiographical memory; Memory and the self; Episodic memories.
} 
Furthermore, two important principles guide most of the autobiographical memory conceptualizations. The first one states that generic knowledge about events and life-time periods is involved in the construction and representation of all memories, even of simple and experience-near events. That is why these memories are never a literally a record of experience but are always integrated with this generic and specific knowledge. It is Conway ${ }^{66}$ who explained with more detail the memory of simple events. A simple episodic memory (SEM) is composed by an episodic element (EE) and a conceptual framework. The episodic element corresponds to a fragmentary and summary representation of experience that is the result of a sensory-perceptual-conceptual-affective processing of external stimuli. But the episodic element is always embedded in a conceptual framework that contextualizes it, interprets it and thus gives to it a personal meaning. Experiences are in general complex and involve more than a simple episodic memory, which is why in general a SEM relates to other SEM in a broader frame giving rise to a complex episodic memory (CEM). Whereas a lot of episodic memories that we formed during the day are if not lost at least inaccessible, a small portion of them become integrated with autobiographical memory knowledge structures - general events, lifetime periods, self-knowledge, etc.-and this integration enables them to remain accessible in long term memory.

The second principle, mainly highlighted by Neisser ${ }^{67}$, Barsalou ${ }^{68}$ and Conway \& Pleydell-Pearce ${ }^{69}$, considers that in everyday memories rememberers move through this nested structure, and so the contents of our personal memories are not stable and punctual, but fluctuate from simple events to more complex and abstract events and vice versa. According to Neisser, "recalling an experienced event is a matter not of reviving a single record but of moving appropriately among nested levels of structure" 70 . And in fact, empirical research done by Barsalou confirms that in free recall protocols, the memories of simple events are invoked together with other kinds of memories of events, like complex and general events ("I went on a diet") and alternative events ("I had not taken a shower"), and even evaluative comments about aspects of the events ("We had a lovely apartment").

Whereas this second version of the content criterion avoids the problems of the first version, it presents some weakness as a criterion for distinguishing different kinds of memories. On the one hand, the distinction between different memories of personally experienced events according to the level of abstraction of events (from experience-near to highly abstract events) is not really conceived as a distinction per se but parallels the episodic/semantic distinction. Shortly after its reintroduction in the field, autobiographical

\footnotetext{
${ }^{66}$ CONWAY, Episodic memories.

${ }^{67}$ NEISSER, Nested structure in autobiographical memory.

${ }^{68}$ BARSALOU, The content and organization of autobiographical memories.

${ }^{69}$ CONWAY; PLEYDELL-PEARCE, The construction of autobiographical memories in the self-memory system.

${ }^{70}$ NEISSER, Nested structure in autobiographical memory, p. 71.
} 
memory was considered as a synonym of episodic memory ${ }^{71}$. But very soon it was distinguished from episodic memory, without for that being defined and analyzed independently from episodic memory. Larsen ${ }^{72}$ conceived autobiographical memory as a subset of the episodic memory system, Rubin ${ }^{73}$ and Baddeley ${ }^{74}$ as a subsystem at the intersection of episodic memories and semantic memories, and Brewer ${ }^{75}$ and Conway \& Pleydell-Pearce ${ }^{76}$ as a superordinate system that includes both episodic memory and semantic facts about the self. However, this superposition or partial overlap between autobiographical memories, episodic memories and semantic memories is not really clarifying. For example, the conception that not all episodic memories are autobiographical memories leads us to the following paradox: episodic autobiographical memories would share a large set of properties with episodic non-autobiographical memories in order for both of them to be considered as part of the same memory kind, but at the same time, they would present a large set of different properties from those belonging to episodic non-autobiographical memories in order for them to be gathered together with semantic autobiographical memories in another memory kind (i.e., autobiographical memories). The same could be said for semantic autobiographical and non-autobiographical memories. What is more, it seems that what reunites episodic and semantic autobiographical memories and distinguishes from other episodic and semantic memories that are not autobiographical is not the nature of the event, but some implicit criterion related to the reference to the self (I will come back to this idea in the last section).

On the other hand, considering that autobiographical memories of experience-near events equate to episodic memories whereas the rest of autobiographical memories constitute a subset of semantic memory ${ }^{77}$ does not provide a better solution with regard to the empirical data that shows the heterogeneous nature of autobiographical memories that are not near-experience. Even if it is granted that experience-near autobiographical memories have many properties in common (similar level of abstraction and generality, similar neural substrate, a high degree of sensory imagery, specific phenomenal feelings, etc $^{78}$ ) and thus it makes sense to cluster them into the category of episodic memory, the same cannot be said of semantic autobiographical memories.

\footnotetext{
${ }^{71}$ TULVING, Elements of Episodic Memory.

${ }^{72}$ LARSEN, Personal context in autobiographical and narrative memories.

${ }^{73}$ RUBIN, The basic-systems model of episodic memory.

${ }^{74}$ BADDELEY, Reflections on autobiographical memory.

${ }^{75}$ BREWER, What is autobiographical memory?

${ }^{76}$ CONWAY; PLEYDELL-PEARCE, The construction of autobiographical memories in the self-memory system

77 CONWAY, Memory and the self; Episodic memories.

${ }^{78}$ See for example RUBIN, Event memory: A theory of memory for laboratory, autobiographical and fictional events.
} 
First, memories of repeated events include spatial and temporal information, that is, contextual information, sensory imagery and emotion ${ }^{79}$, similarly to episodic memory. Also, the brain areas activated during retrieval are more similar-even if they do not overlap - to episodic memory than to semantic memory: they include the hippocampus and the medial temporal lobe. The phenomenal feeling of re-experiencing is also generally present in memory of repeated events.

Secondly, the nature of autobiographical facts, like "My son was born the 15th June 1999" or "I used to live in Brown Street" is quite complex. Although some literature provide evidence of the similarity between autobiographical facts and semantic memory ${ }^{80}$, a recent review article about amnesic patients with medial temporal lobe lesion made by Grilli \& Verfaellie ${ }^{81}$ comes to a different conclusion. According to this review, memory of autobiographical facts is impaired in amnesic patients, and this shows that memory of autobiographical facts partially depends on the medial temporal lobe and thus, that they share mechanisms with episodic memory. Also, Martinelli \& al. ${ }^{82}$ state that semantic autobiographical memories seem to recruit basically the same brain structures as does episodic memory, but to a lesser extent and excluding the hippocampus. The problem is that notions like autobiographical facts and semantic autobiographical memories seem to refer to a variety of memories that includes friend's names and personal addresses, memories that are closely associated with a unique event, such as "My son was born the 15th June 1999", and memories that refer to lifetime periods, such as "I used to live in Brown Street". It is probable that memories of friend's names and addresses are more semantic-because of their frequency-than other kinds of memories associated with events. It is also probably that memories associated with specific events would include more spatio-temporal information, sensory imagery and emotional content than memories associated with general events or lifetime periods. However, in real life memories the content is not always the same but fluctuates from the general to the specific and vice versa, so it is also probable that even memories of general events and lifetime periods can also be experienced with sensory imagery and some emotional content, with a consequent feeling of remembering. To someone's question as to if I had always lived in the same house or not, I could simply reply "No, I used to live in Brown Street" and simultaneously a mental image of my house and the street could come to my mind as well as some feeling of nostalgia.

There is also a third kind of autobiographical memories that are not experiencenear but present some similarities with episodic memories: autobiographically significant

\footnotetext{
${ }^{79}$ RENOULT et al., Personal semantics: at the crossroads of semantic and episodic memory.

${ }^{80}$ Idem. PICARD, et al., Functional independence within the self-memory system.

${ }^{81}$ GRILLI; VERFAELLIE, Personal semantic memory: Insights from neuropsychological research on amnesia.

${ }^{82}$ MARTINELLI et al., Neural substrates of the self-memory system.
} 
concepts $^{83}$, which refers to semantic concepts related to events (such as famous faces and names). This kind of memories seem to involve the medial temporal lobe and so engage both the episodic memory system and the semantic one. They are in general characterized by a high degree of sensory imagery and emotional content and include spatial and temporal information. Larsen ${ }^{84}$ also mentions a similar case to autobiographically significant concepts: narrative memories. Narrative memories are memories about events not directly experienced by the rememberer but learnt indirectly by testimony, such as events learnt by the news or read in a book or told by someone, whose content is thus not personal but, like autobiographically significant concepts, are nonetheless autobiographical because they have the property of being tied to a personal event. The personal context corresponds to the moment in which the rememberer received the message, news or information ${ }^{85}$, and this moment refers not only to the time and location but also can include personal meaning and have an emotional tone. It would be expected that narrative memories could be explained in a similar way to autobiographically significant concepts, astride the episodic memory and the semantic one.

All these cases point to the fact that autobiographical memories that are not experience-near are very heterogeneous and cannot be clustered into the category of semantic autobiographical memories, in opposition to episodic autobiographical memories. Specific events, general events, repeated events, lifetime periods and other kinds of personal memories can be understood neither as similar to episodic memory nor as a sub-domain of semantic memory; nor even as a continuum that goes from the most specific and episodic elements to the most abstract and semantic ones, like most of the nested models of autobiographical memories propose. Furthermore, some evidence indicates that memories of experience-near events do not really belong to a homogenous category, and thus cannot always considered to be episodic. In fact, there are some memories of experience-near events that are poor in imagery and emotional tone, do not depend anymore upon the MDL (and thus upon the hippocampus), and present a large set of phenomenal properties that are different from those generally attributed to episodic memory. The reason is the process of semantization that affects some episodic memories due to remoteness and aging ${ }^{86}$.

To conclude, this second version of the content criterion does not offer a good criterion to distinguish different kinds of memories neither. Similarities and differences between autobiographical memories of events cannot be explained according to the level

\footnotetext{
${ }^{83}$ RENOULT et al., Personal semantics: at the crossroads of semantic and episodic memory.

${ }^{84}$ LARSEN, Personal context in autobiographical and narrative memories.

${ }^{85}$ Idem, p. 61. The notion of narrative memory is very similar to the more recent and familiar notion of "flashbulb memory".

${ }^{86}$ PIOLINO, et al. Episodic autobiographical memories over the course of time: cognitive, neuropsychological and neuroimaging findings.
} 
of abstraction and generality of the event remembered. Although the level of abstraction of the content remembered may play some role at the moment of distinguishing different kinds of long-term individual memory representations, it does not provide by itself neither a sufficient criterion nor a significant one. It seems thus that the nature of memories are quite independent of the nature of the content that constitutes their intentional object, either when the content is defined in function of the absence or presence of temporal and contextual information, or in function of its level of abstraction and generalization.

\section{The phenomenal criterion}

Unlike the content criterion, which is focused on the properties of the intentional object of memories in order to distinguish different memory kinds, the phenomenal criterion establishes this distinction according to the particular phenomenology of memories. With time, the phenomenology of memory acquired more importance in Tulving's memory model and thus memory kinds were redescribed in phenomenal terms: instead of being mainly defined in terms of the kind of information that is encoded, stored and retrieved, they were redefined in terms of the kind of subjective experience that accompanies the operations of the system at retrieval. McCormack ${ }^{87}$ called this new way of defining episodic memory the experiential description. This criterion proposes that the essential characteristic for identifying memory kinds is the type of conscious awareness that accompanies a memory experience. According to Tulving ${ }^{88}$, whereas the notion of autonoetic awareness characterizes episodic memory, semantic memory is characterized by the notion of noetic awareness. The concepts of noetic and autonoetic awareness, however, are not well defined. For example, Tulving describes autonoesis as referring "to the kind of consciousness awareness that characterizes conscious recollection of personal happenings" 89 . This description is a tautological definition; it does not say what characterizes the awareness of recollecting personally experienced events. In fact, Tulving added to autonoesis another three essential features of episodic memory which can give a clue about the meaning of this term: mental time travel, self and chronesthesia, all of which are highly related. Mental time travel refers to the possibility for the rememberer “to travel back in his or her mind to an earlier occasion or situation in the rememberer's life, and to mentally relive the experienced and thought-about happenings" ${ }^{90}$. The self refers to the agent who does the travelling, and chronesthesia to the experience of subjective time that recollection allows. These characteristics summarize the meaning of the particular consciousness that accompanies recollection, and so autonoesis could be

\footnotetext{
${ }^{87}$ McCORMACK, Attributing episodic memory to animals and children.

${ }^{88}$ TULVING, Memory and consciousness.

${ }^{89}$ TULVING, Episodic memory and autonoesis: Uniquely human?, p. 15.

${ }^{90}$ Idem, p. 14.
} 
defined as the awareness that arises from the ability to subjectively and mentally time travel to the past, which allows the self to represent and re-experience a past event. Therefore, essential to the notion of autonoesis is the idea of re-experiencing past experiences ${ }^{91}$. Because of these characteristics, it "confers the special phenomenal flavor to the remembering of past events, the flavor that distinguishes remembering from other kinds of awareness, such as those characterizing perceiving, thinking, imagining, or dreaming" ${ }^{2}$. Noesis, on the other side, only allows the rememberer to be aware of the content of the memory. When information about the personal past is remembered without any recollective experience, that is, with noetic awareness, it is strictly only known and corresponds to the semantic memory system. That is why this distinction between remembering a past experience in an autonoetic or a noetic manner corresponds to other famous distinction introduced by Tulving in the psychological field between remembering some event from the personal past and knowing some event from the (personal) past.

Some amnesic patients would constitute empirical evidence for this dissociative hypothesis: those who have source amnesia and those with medial temporal lobe damage which principally affects the hippocampus. Source amnesia is described as the retention and retrieval of factual content of an episode without any recollection of the episode itself in which that factual content was acquired ${ }^{93}$. Patients with frontal lobe damage, elderly individuals and patients in early stages of Alzheimer's disease are among the groups who have this sort of memory disorder, which was already remarked by Claparède ${ }^{94}$ in the study of his Korsakoff's patient. The same dissociation is presented in amnesic patients with damage to the hippocampus. It is of interest to consider patients whose hippocampus has been damaged early in life ${ }^{95}$, because it shows that they can attain average levels of speech, language competence, literacy and factual knowledge without being able to remember events in daily life and spatial and temporal locations. But probably the most important and paradigmatic case of loss of autonoetic consciousness without loss of noetic consciousness is the amnesic patient K.C. ${ }^{96}$ who had global anterograde amnesia and retrograde episodic amnesia. K.C.'s implicit and procedural memories were preserved. He still possessed stored semantic facts about the world and also about his life, and could still learn under special conditions some new facts. However, he was unable to recollect

\footnotetext{
91 TULVING, Chronesthesia: awareness of subjective time, p. 313.

92 TULVING, Memory and consciousness, p. 3.

${ }^{93}$ EVANS; THORN, Two types of posthypnotic amnesia: Recall amnesia and source amnesia; SCHACTER et al., Retrieval without recollection: An experimental analysis of source amnesia; WHEELER, Episodic memory and autonoetic awareness.

${ }^{94}$ CLAPAREDE, Recognition et moitié.

95 VARGHA-KHADEM, et al. Differential effects of early hippocampal pathology on episodic and semantic memory.

96 TULVING, Memory and consciousness
} 
specific events in which he himself participated or that he witnessed, whether experienced long ago or in more recent times. In fact, the autobiographical knowledge about his past relied completely on his semantic memory: he showed no feeling of re-experiencing and his recollections completely lacked the subjective re-evoking of the emotional and contextual details that defined episodic memory ${ }^{97}$. Even episodes in K.C.'s life that are supposed to be personal tragedies are remembered as simple decontextualized facts, without any emotional tone, vividness or intensity. K.C. is not the only example and other similar cases have been reported in the literature ${ }^{98}$.

More recently, the psychologist Stanley Klein ${ }^{99}$ has defended a similar position to Tulving's experiential definition episodic memory. According to Klein, "a memory experience is not the nature of the content presented to awareness, but the manner in which awareness becomes associated with the content during the act of retrieval" ${ }^{100}$. Information about an event's what, where and when, that is, about the temporal and spatial context of some happening, even if it is self-referential, can also be displayed in reports of semantic experience. Unlike Tulving's SPI model, Klein considers that this information is unspecified prior to its demarcation as semantic or episodic during the act of retrieval. Two case studies are in favor of his account. The first one refers to amnesic patients similar to K.C., as well as developmental amnesic children, who are unable to relive their personal past, and thus remembering it in a proper way, but are nonetheless able to re-learn the temporal, spatial and self-referential information about their own past even if less detailed than non-amnesic people. The second case is a little more controversial, because it refers to a patient who had a temporary memory disorder due to an accident and was exclusively interviewed at that time by Klein. According to Klein \& Nichols ${ }^{101}$, during some time after the accident this patient, who is known as R.B., was able to describe events of his life with contextually rich details but without the feeling of mine-ness that would be proper to autonoetic awareness: "when I recall memories of my past I intellectually know they are about me. It just does not feel like it ... when I remember scenes from before the injury they do not feel as if they happened to me -though intellectually I know they did" ${ }^{102}$.

In conclusion, the criterion based on the phenomenology of the experience breaks the equation between episodic memory and memory of events. The retrieval of information about some experience-near past event does not need to be necessarily accompanied by

\footnotetext{
${ }^{97}$ ROSENBAUM, et al. The case of K.C.: Contributions of a memory-impaired person to memory theory, p. 1008

${ }^{98}$ NADEL; MOSCOVITCH, Memory Consolidation, Retrograde Amnesia and the Hippocampal Complex, p. 219.

${ }^{99}$ KLEIN, The two selves: Their metaphysical commitments and functional independence; What memory is?

${ }^{100}$ Idem, p. 45.

${ }^{101}$ KLEIN; NICHOLS, Memory and the sense of personal identity.

${ }^{102}$ KLEIN, What memory is?, p. 47
} 
autonoetic awareness; it can also come with noetic awareness. What is more, the memory distinction based on the phenomenology can account without problem what the second version of the content criterion could not: the process of semantization of memories of experience-near events due to remoteness and aging ${ }^{103}$.

The phenomenal criterion presents other advantages in relation to the second version of the content criterion. In general terms, it avoids multiplying different memory systems and kinds and thus analyzing a single memory occurrence as belonging to or sharing properties with different memory systems (such as semantic autobiographical memories). It also avoids clustering under the same category: semantic autobiographical memory, all the memory of events that are not experience-near, which do not really belong to a homogenous class (as the empirical data concerning repeated events, autobiographical facts and autobiographical significant concepts have shown). Memories of events can be remembered autonoetically or noetically, and this is not completely determined by the level of abstraction and generality of the event remembered. That is why a memory of a repeated or general event can be remembered with autonoesis, and thus present more similarities with some memories of experience-near events than with other memories of events of a high level of abstraction. It is in fact the mode of retrieval which determines the kind of awareness that accompanies the memory retrieval. Finally, this criterion does not distinguish different kinds of memories of events, but different kinds of memories tout court. So it also accounts for memories of individuals, that is, of objects, people and places, which are not actually reducible to events and were in general excluded from most models of autobiographical memory. It explains thus why the memory of my partner who is currently absent from home, or of my dead father, can come with a subjective feeling of travelling back to the past.

Nonetheless, the phenomenal criterion is not exempt of criticism. First, as I have already highlighted, the notions of autonoetic and noetic awareness are quite obscure. Since its introduction by Tulving, autonoesis has been considered by many researchers as synonym of reexperiencing and consciously reliving the past. Authors insist that in episodic memory the rememberer "view[s] these events as they would originally have been seen through her own eyes" ${ }^{104}$, and it "is for her just as if the scenario were present" ${ }^{105}$. Nonetheless, these characterizations are rather vague and imprecise to distinguish memory kinds. What is more, autonoesis, or the feeling of reliving and reexperiencing the past does not appear as an all-or-none phenomenon. Only traumatic memories related to PSTD are cases that truly deserved the qualifying "reexperience" and "reliving": the intrusive visual memories that characterize PTSD convey a sense of immediate perceptual

\footnotetext{
${ }^{103}$ PIOLINO, et al. Episodic autobiographical memories over the course of time: cognitive, neuropsychological and neuroimaging findings.

${ }^{104}$ Idem, p. 2318.

${ }^{105}$ CHENG, et al. Dissociating memory traces and scenario construction in mental time travel, p. 15.
} 
experience because they are processed as real and as a real threat ${ }^{106}$. Other cases of episodic memories do not imply a real feeling of reexpericing or reliving the past event. In fact, this variability of the sense of reliving a past experience is taken into consideration in different versions of the Autobiographical Memory Characteristics Questionnaire that demand the rememberers to address the vividness and the level of recollective experience of their memories using a seven-point Likert-type scale ${ }^{107}$. Therefore, autonoesis seems to be better conceived as a gradual phenomenal property of memories that can come in different degrees, and not as a particular mode of awareness among two possible and opposite modes.

Secondly, although it is possible to conceive the phenomenal criterion as the key criterion to establish distinctions between memory kinds, it is not clear neither that Tulving and subsequent researchers conceived it independently of the content remembered (except probably only for Klein), nor that it is possible-and plausible-to conceive it that way. In one of Tulving's writings, episodic memory "is defined in terms of criteria such as the system's function-what the system does, how it works, the kind of 'information' that it deals with, its relations to other systems, and its neural substrates” ${ }^{108}$, suggesting that the content of a memory plays some role in order to determine the memory kind to which this memory belongs. An episodic memory, that is, an experience remembered with autonoetic awareness, does not seem to be a memory of any kind of information.

Rubin $^{109}$, on the other hand, is less equivocal than Tulving: for him, memories that are highly correlated with a sense of reliving and other measures of reliving (such as mental time travel) are memories presented through a particular kind of vehicle: visual and spatial imagery. Whereas he does not explicitly correlate phenomenology and content but phenomenology and vehicles of representation, this explicit correlation carries in certain way an implicit correlation between content and phenomenology. The nature of visual and spatial imagery or "scenes", as Rubin calls it, puts certain constraints on the kinds of intentional object that our memories may have. Because the construction of a unique scene resultant from a sort of superposition form the exposure to multiple perspectives of the same scene does not mainly differ from the superposition of repeated scenes implied in the construction of scenes of repeated events, Rubin considers that repeated events are similar to unique and simple events ${ }^{110}$. But the relation between scenes and more abstract and

\footnotetext{
${ }^{106}$ HOLMES; MATTHEWS, Mental imagery in emotion and emotional disorders.

107 JOHNSON et al., Phenomenal characteristics of memories for perceived and imagined autobiographical events. BOYACIOGLU; AKFIRAT, Development and psychometric properties of a new measure for memory phenomenology: The autobiographical memory characteristics questionnaire.

108 TULVING, Episodic memory and autonoesis: Uniquely human?, p. 10.

${ }^{109}$ RUBIN, Event memory: A theory of memory for laboratory, autobiographical and fictional events.

${ }^{110}$ Also RENOULT et al. Personal semantics: at the crossroads of semantic and episodic memory.
} 
generic events is not so simple. In some cases it is possible to construct a sort of generic image that does not correspond to any single episodic moment, whereas in other cases a similar generic image is not possible:

Generic personal memories are constrained by the abstracting properties of the relevant perceptual systems. Thus, I can have a generic personal memory of 'going out on the beach' during some vacation but not of 'going on vacation' where that includes going hiking in the mountains, going swimming at a beach, and visiting a major city ${ }^{111}$.

So it seems that when our memories are directed to some general events, extendures and lifetime periods, the only imagery that can accompany these retrievals to give to them a sort of derivative recollective phenomenology are scenes of less general events that are subsumed under them or of things or people involved, that is, images of what can be representable through the corresponding perceptual systems.

This correlation between phenomenology, content and vehicles of representation depends on the assumption that visual and spatial imagery is what gives a special kind of phenomenology to memories. Nonetheless, this assumption is not exempt of problems: scenes alone cannot account for the special phenomenology that is characteristic of some memories because, as it was explained as part of the criticism to the vehicle criterion, memories of specific events can be devoid of visual and spatial imagery; scenes can also be part of memories with noetic awareness, and visual and spatial imagery are also part of the construction of different kinds of non-mnemonic mental states.

On the other hand, there is certainly some correlation between the phenomenology, content and means of representation of memories. Nonetheless, these possible correlations have been for now more sketched that studied in deep, and in fact seem difficult to define. Rubin's proposal of a relation between vehicles of representation and memory contents conceived according to its level of abstraction and generalization present some limitations. Although Tulving ${ }^{112}$ himself implied that there were multiple properties that establish a difference between episodic and semantic memory, he did not explicitly explain how these properties interrelate with each other in order to determine the ones that are essential and the ones that are secondary. His later emphasis on the major importance of the phenomenal property to define memory kinds (autonoesis versus noesis), does not seem to be completely convincing.

\section{A promising line for future research: the affective criterion}

\footnotetext{
${ }^{111}$ BREWER, What is autobiographical memory?, p. 30.

112 TULVING, Elements of Episodic Memory. Episodic memory and common sense: how far apart?
} 
This analysis shows that for now, none of the criteria proposed in the literature to distinguish memory kinds is completely satisfactory. Some criteria should be directly discarded, such as the grammatical and causal criteria, because they do not provide any credible hint of the memory properties that may be the cause of different natural kinds. Some other criteria seem more promising, but neither as they were formulated nor isolated from one another. The last remarks done in the former section suggest that a kind of correlation between the vehicle of representation, the content and the phenomenology may be better suited to account for the varied nature of our memories. This interrelation, which is probably not easy to characterize, needs certainly to be object of a detailed and deep research. It is not the aim of this article to provide such an explanation: its main purpose is to expound the different criteria proposed to distinguished memory kinds and highlight their problems and challenges. Nonetheless, the rest of this section mentions briefly a hypothesis that may be worth exploring.

Many authors, especially coming from philosophy, have stated that what really characterizes episodic memories and distinguishes them from semantic ones is the presence of the past self in the representation of the experience remembered. Whereas in episodic memory, the events represented are presented as having happened in the past to me, in semantic memory, on the contrary, those events do not present any reference to the self. This reference to the self has been in some cases tied to the notion of autonoesis: autonoetic awareness is not only awareness directed to something past, but also directed to onself, more specifically, to the past self who was the subject of the past experience. For example, Chen \& al. have explicitly defined autonoesis as "the awareness that oneself has been part of the recalled event"113; also Bermudez ${ }^{114}$ has stated that episodic memory involves an awareness that the event happened to me, to give some examples. This selfreference can be accounted by two means. Either the self is directly present on the memory content (for example, through the integration of a memory or conceptual knowledge of my past self into the construction of the memory of a past experience), or is part of the process of retrieval (option that would be more compatible with memory processes than with memory systems). Rowlands ${ }^{115}$ has recently proposed this last conception: the act of remembering-which can be understood as the process of remembering-subsumes the event remembered under a specific mode of presentation that, as a result, entails a change in the way the event is remembered. Because of this mode, the past event is presented "as one that has been formerly witnessed, orchestrated or otherwise encountered by the rememberer" ${ }^{116}$, that is, in intrinsic connection to the past self.

\footnotetext{
${ }^{113}$ CHENG, et al. Dissociating memory traces and scenario construction in mental time travel, p. 4.

${ }^{114}$ BERMUDEZ, Memory and Self-consciousness.

${ }^{115}$ ROWLANDS, Memory and the self: Phenomenology, science and autobiography.

${ }^{116}$ Idem, p. 49
} 
Whereas the line of research that proposes the presence or the absence of the self as a criterion to distinguish different memory kinds is quite promising, it needs further development in order to avoid a similar criticism to the previously mentioned, such as the semantization process suffered by some episodic memories due to remoteness and aging.

One possible way of refining this idea and avoid this possible criticism, consists in exploring a more elaborated and precise way in which the self can be present or not in our memories: through affect. Affect is essentially relational, that is, is the product of the relation between the individual and her environment, and thus represents how an individual is moved and influenced in terms of harms, benefits, morality or self-image by the dynamic and continuous environmental changes. While some of our memories seem to be directed towards objective and impersonal properties of past events and experiences, others represent not the past experience or event in itself, independently of the rememberer, but the way in which the rememberer was affected by that past experience or event. The focus of this last kind of memories is the affective significance of a past experience, and not its descriptive impersonal properties. This affection can be explicitly attended to as the intentional object of the memory, or can appear in a pre-attentive or pre-reflective way; it can take the form of interoceptive bodily sensations, action tendencies, and even motor behaviors. The interplay between a special type of memory content: affect, carried by specific vehicles of representation: bodily sensations, action tendencies, etc., and being susceptible of different levels of consciousness (reflectivity, prereflectivity, etc.), would determine the particular phenomenal properties of the memory. According to this proposal, our everyday memories are situated somewhere between two extremes: either we remember events and experiences objectively, completely detached from the rememberer, or we remember them through their past affection, and it is through this affection that the rememberer is present in the content of memory. Close to the first extreme, there are memories of past events that contain a minimal reference to the self: events are presented as formerly witnessed, orchestrated or encountered by the rememberer, so the presence of the self in the memory content is reduced to a simple past spectator or orchestrator. At the end of the opposite extreme, there are those "affective" memories that imply a real emotional reexperience of the past event, such as in PTSD. Because of the varied way in which affection can be represented and consciously attended to, our affective memories would occupy different points in this continuum, and entail different phenomenal properties, or similar phenomenal properties but in different degrees. In fact, this conceptual outline could be matched with relatively recent attempts to integrate the amygdala to the standard model of episodic memory in order to account 
for the emotional properties and significance of the events remembered through the episodic memory system ${ }^{117}$.

More research should be pursued in this line, because the presence of the self through affection appears at first sight as an excellent starting-point in order to identify the possible interrelations between key components that account for the existence of different kinds of long-term individual memory representations.

\section{Acknowledgements}

This research was mainly supported by a grant funded by the Fondation Maison des sciences de l'homme and the Centre Universitaire de Norvège à Paris (France). It was presented at the Centre for the Study of Mind in Nature of the University of Oslo (Norway) in September 2016. I would like to thank to the audience, especially to Olav Gjelsvik, Sebastian Watzl and Frøydis Gammelsæter for their feedback.

\section{References}

Allen, P. A., Kaut, K. P., \& Lord, R. R. Emotion and episodic memory. In: DERE, E., EASTON, A., NADEL, L., \& HUSTON, J. P. (Eds.). Handbook of episodic memory. Handbook of behavioral neuroscience. Elsevier, vol. 18, 2008, 115-132.

AMBERBER, M. (Ed.), The Language of Memory in a Crosslinguistic Perspective. Amsterdam: John Benjamins Publishing Company, 2007.

ARISTOTLE (350 BC) On Memory and Reminiscence.

Baddeley, A. Reflections on autobiographical memory. In: BERNTSEN, D. \& RUBIN, D. (Eds.). Understanding Autobiographical Memory. Cambridge: Cambridge University Press, 2012.

Barsalou, L. The content and organization of autobiographical memories. In: NEISSER, U. Neisser \& E. Winograd (Eds.). Remembering reconsidered. Cambridge: Cambridge University Press, 1988.

BARTLETT, F.C. Remembering. Cambridge: Cambridge University Press, 1932.

Bermudez, J. L. Memory and Self-consciousness. In: BERNECKER, S. \& MICHAELIAN, K. (Eds.). The Routledge handbook of philosophy of memory. New York, NY: Routledge, 180-191, 2017.

\footnotetext{
${ }^{117}$ DOLAN, et al., Dissociable temporal lobe activations during emotional episodic memory retrieval. ALLEN et al., Emotion and episodic memory. YONELINAS; RITCHEY, The slow forgetting of emotional episodic memories: an emotional binding account.
} 
BERNECKER, S. The Metaphysics of Memory. Dordrecht: Springer, 2008.

BERNECKER, S. Memory: A philosophical Study. Oxford, Oxford University Press, 2010.

BLAXTON, T. Investigating dissociations among memory measures: support for a transfer appropriate processing framework. Journal of Experimental Psychology: Learning, Memory and Cognition, 15, 657-658, 1988.

BOYACIOGLU, I., \& AKFIRAT, S. Development and psychometric properties of a new measure for memory phenomenology: The autobiographical memory characteristics questionnaire. Memory, 23(7), 1070-1092, 2015.

Boyd, R. Homeostasis, species and higher taxa. In: WILSON, R. (Ed.). Species: New Interdisciplinary Essays. Cambridge, MA: MIT Press, 141-185, 1999.

Brewer, W. What is autobiographical memory? In: RUBIN, R. (Ed.). Autobiographical Memory. Cambridge: Cambridge University Press, 25-49, 1986.

CABEZA, R., \& Moscovitch, M. Memory systems, processing modes, and components: functional neuroimaging evidence. Perspectives on Psychological Science, 8(1), 49-55, 2013.

CHENG, S., WERNING, M., \& SUDDENDORF, T. Dissociating memory traces and scenario construction in mental time travel. Neuroscience \& Biobehavioral Reviews, 60, 82-89, 2016.

CLAPARÈDE, E. Recognition et moitié. Archives de psychologie, 11, 79-90, 1911.

CLAYTON, N.S. \& DICKINSON, A. Episodic-like memory during cache recovery by scrub jays. Nature, 395, 272-274, 1998.

Conway, M. A structural model of autobiographical memory. In: CONWAY, M. RUBIN, D., SPINNLER, H., \& WAGENAAR, W. (Eds.). Theoretical perspectives on autobiographical memory. Dordrecht, Kluwer Academic Publisher, 167-194, 1992.

Conway, M. A. Autobiographical knowledge and autobiographical memory. In: RUBIN, D. (Ed.). Remembering our past: Studies in autobiographical memory. Cambridge: Cambridge University Press, 67-93, 1995.

CONWAY, M. Memory and the self. Journal of Memory and Language, 53, 594-628, 2005.

CONWAY, M. Episodic memories. Neuropsychologia, 47, 2305-2313, 2009.

CONWAY, M., \& PLEYDELL-PEARCE, C. The construction of autobiographical memories in the self-memory system. Psychological review, 107, 261-288, 2000.

DOLAN, R. J., LANE, R., CHUA, P., \& FLETCHER, P. Dissociable temporal lobe activations during emotional episodic memory retrieval. Neuroimage, 11(3), 203-209, 2000. 
EVANS, F. \& THORN, W. Two types of posthypnotic amnesia: Recall amnesia and source amnesia. The International Journal of Clinical and Experimental Hypnosis, 14(2), 162-179, 1966.

FARAH, M. J. The neurological basis of mental imagery: A componential analysis. Cognition, 18, 245-272, 1984.

FERNANDEZ, J. The intentionality of memory. Australasian Journal of Philosophy, 84(1), 39$57,2006$.

GHAHAM, K.S., SIMONS, J., PRATT, K.H., PATTERSON, K., \& HODGES, J.R. Insights from semantic dementia on the relationship between episodic and semantic memory. Neuropsychologia, 38, 313-324, 2000.

GREENBERG, D. L., \& RUBIN, D. C. The neuropsychology of autobiographical memory. Cortex, 39(4-5), 687-728, 2003.

GRILliA, M. \& VERFAELliE, M. Personal semantic memory: Insights from neuropsychological research on amnesia. Neuropsychologia, 61, 56-64, 2014.

HASSABIS, D., KUMARAN, D., \& MAGUIRE, E. Using imagination to understand the neural basis of episodic memory. The Journal of Neuroscience, 27, 14365-14374, 2007.

HOLMES, E. A., \& MATHEWS, A. Mental imagery in emotion and emotional disorders. Clinical psychology review, 30(3), 349-362, 2010.

JOHnsON, M. K., FOLEY, M. A., SUENGAS, A. G., \& RAYE, C. L. Phenomenal characteristics of memories for perceived and imagined autobiographical events. Journal of Experimental Psychology: General, 117(4), 371-376, 1988.

KLEIN, S. The two selves: Their metaphysical commitments and functional independence. New York, Oxford University Press, 2014.

KLEIN, S. What memory is? WIREs Cognitive Science, 5(2), 1-38, 2014.

KLEIN, S. \& NICHOLS, S. Memory and the sense of personal identity. Mind, 121, 677-702, 2012.

KOLODNER, J. L. Maintaining organization in a dynamic long-term memory. Cognitive Science, 7(4), 243-280, 1983.

KOLODNER, J. L. Retrieval and Organizational Strategies in Conceptual Memory: A Computer Model. Hillsdale: Lawrence Erlbaum Associates, 1984.

LACKEY, J. Memory as a Generative Epistemic Source. Philosophy and Phenomenological Research, 70(3), 636-658, 2005.

LARSEN, S. Personal context in autobiographical and narrative memories. In: CONWAY, M., RUBIN, D., SPINNLER, H. \& WAGENAAR, W. (Eds). Theoretical Perspectives on Autobiographical Memory. Dordrecht: Kluwer Academic Publisher, 53-74, 1992. 
Linton, M. Ways of searching and the contents of memory. In: RUBIN, R. (Ed.). Autobiographical Memory. Cambridge: Cambridge University Press, 1988.

MACHERY, E. Doing Without Concepts. Oxford: Oxford University Press, 2009.

MALCOLM, N. Knowledge and Certainty. London: Cornell University Press, 1963.

MARGOLIS, J. Remembering. Mind, 86, 186-205, 1977.

MARIAN, V., \& NEISSER, U. Language-dependent recall of autobiographical memories. Journal of Experimental Psychology: General, 129, 361-368, 2000.

MARTIN, C. B. \& DEUTSCHER, M. Remembering. The Philosophical Review, 75(2), 161196, 1966.

MARTINELLI, P., SPERDUTI, M. \& PIOLINO, P. Neural substrates of the self-memory system. Human Brain Mapping, 34, 1515-1529, 2013.

McCormack, T. Attributing episodic memory to animals and children. In: McCORMACK, T. \& HOERL, C. (Eds.). Time and Memory. New York: Oxford University Press, 285-313, 2001.

MICHAELIAN, K. Opening the doors of memory: is declarative memory a natural kind? Wiley Interdisciplinary Reviews: Cognitive Science, 6(6), 475-482, 2015.

MICHAELIAN, K. Mental Time Travel: Episodic Memory and Our Knowledge of the Personal Past. Cambridge, MA: The MIT Press, 2016.

MOSCOVITCH, M. Memory and working with memory: A component process model based on modules and central systems. Journal of Cognitive Neuroscience, 4, 257-267, 1992.

MUNSAT, S. The Concept of Memory. New York: Random House, 1967.

NADEL, L. \& MOSCOVITCH, M. Memory Consolidation, Retrograde Amnesia and the Hippocampal Complex. Current Opinion in Neurobiology, 7, 217-227, 1997.

NAYLOR, A. Remembering-that: episodic vs. semantic. Philosophical Psychology, 24(3), 317322, 2011.

Neisser, U. Nested structure in autobiographical memory. In: RUBIN, R. (Ed.). Autobiographical Memory. Cambridge, Cambridge University Press, 71-81, 1986.

Nikulin, D. Memory in Ancient Philosophy. In: NIKULIN, D. (Ed.). Memory: A history. Oxford University Press, 35-91, 2015.

PAIVIO, A. Mental Representations: A Dual Coding Approach. Oxford, Oxford University Press, 1986. 
PICARD, L., MAYOR-DUBOIS, C., MAEDER, P., KALENZAGA, S., ABRAM, M., DUVAL, C. EUSTACHE, F., ROULET-PEREZ, E. \& PIOLINO, P. Functional independence within the self-memory system. Cortex, 49, 1463-1481, 2013.

PIOLINO, P., DESGRANGES, B., \& EUSTACHE, F. Episodic autobiographical memories over the course of time: cognitive, neuropsychological and neuroimaging findings. Neuropsychologia, 47(11), 2314-2329, 2009.

Renoult, L., DAVidson, P., PAlombo, D., MOscovitCH, M. \& LeVine, B. Personal semantics: at the crossroads of semantic and episodic memory. Trends in Cognitive Sciences, 16(11), 550-558, 2012.

Roediger, H. \& McDermott, K. Implicit memory in normal human subjects. In: SPINNLER, H. \& BOLLER, F. (Eds.). Handbook of Neuropsychology. Amsterdam: Elsevier, Vol. 8, 63-131, 1993.

ROSENBAUM, R., KOHLER, S., SCHACTER, D., MOSCOVITCH, M., WESTMACOTT, R., BLACK, S., GAO, F. \& TULVING, E. The case of K.C.: Contributions of a memoryimpaired person to memory theory. Neuropsychologia, 43, 989-1021, 2005.

ROWLANDS, M. Memory and the self: Phenomenology, science and autobiography. Oxford University Press, 2017.

RUBIN, D. The basic-systems model of episodic memory. Perspectives on Psychological Science, 1(4), 277-311, 2006.

RUBIN, D. Event memory: A theory of memory for laboratory, autobiographical and fictional events. Psychological Review, 122(1), 1-23, 2015.

RUSSELL, B. The Problems of Philosophy, 1912. Available at: http://ditext.com/russell/russell.html

SAUNDERS, J. Does all memory imply factual memory? Analysis, 25(3), 109-115, 1965.

SCHACTER, D., HARBLUK, J. \& McLACHLAN, D. Retrieval without recollection: An experimental analysis of source amnesia. Journal of Verbal Learning and Verbal Behavior, 23, 593-611, 1984.

SCHRAUF, R.W. Bilingual autobiographical memory: Experimental studies and clinical cases. Culture and Psychology, 6, 387-417, 2000.

Squire, L.R. Memory systems: A biological concept. In: ROEDIGER, H., DUDAI, Y. \& FITZPATRICK, S. (Eds.). Science of Memory: Concepts. Oxford, Oxford University Press, 339-344, 2007.

SQUIRE, L.R., \& ZOLA, S.M. Episodic memory, semantic memory, and amnesia. Hippocampus, 8, 205-211, 1998. 
TEKCAN, A. İ., YILMAZ, E., KAYA KIZILÖZ, B., KARADÖLLER, D. Z., MUTAFOĞLU, M., \& AKTAN ERCIYES, A. Retrieval and phenomenology of autobiographical memories in blind individuals. Memory, 23(3), 329-339, 2015.

Tulving, E. Episodic and semantic memory. In: TULVING, E. \& DONALDSON, W. (Eds.). Organization of Memory. New York: Academic Press, 381-402, 1972.

TULVING, E. Elements of Episodic Memory. Oxford, Oxford University Press, 1983.

TUlVING, E. Memory and consciousness. Canadian Psychology, 26, 1-12, 1985.

Tulving, E. Organization of memory: Quo vadis? In: GAZZANIGA, M. S. (Ed.). The Cognitive Neurosciences. Cambridge: The MIT Press, 753-847, 1995.

Tulving, E. Study of memory: processes and systems. In: FOSTER, J. K. \& JELICIC, M. (Eds.). Memory: Systems, Process, or Function? New York, NY: Oxford University Press, 11-30, 1999.

TULVING, E. Episodic memory and common sense: how far apart? Philosophical Transactions of the Royal Society of London. Series B, Biological Sciences, 356(1413), 1505-1515, 2001.

Tulving, E. Chronesthesia: awareness of subjective time. In: STUUS, D. \& KNIGHT, R. (Eds.). Principles of frontal lobe functions. New York, NY: Oxford University Press, 311-325, 2002b.

TULVING, E. Episodic memory: From mind to brain. Annual Review of Psychology, 53, 1-25, 2002b.

Tulving, E. Episodic memory and autonoesis: Uniquely human? In: TERRACE, H. S., \& METCALFE, J. (Eds.). The Missing Link in Cognition. New York, NY: Oxford University Press, 4-56, 2005.

VARGHA-KHADEM, F., GADIAN, D., WATKINS, K., CONNELLY, A., VAN PAESSCHEN, W. \& MISHKIN, M. Differential effects of early hippocampal pathology on episodic and semantic memory. Science, 277 (5324), 376-80, 1997.

Wheeler, M.A. Episodic memory and autonoetic awareness. In: TULVING, E. \& CRAIK, F. (Ed.). The Oxford Handbook of Memory. New York, NY: Oxford University Press, 297-312, 2000.

WOLLHEIM, R. The thread of life. Glasgow, Cambridge University Press, 1984.

YONELINAS, A. P., \& RITCHEY, M. The slow forgetting of emotional episodic memories: an emotional binding account. Trends in cognitive sciences, 19(5), 259-267, 2015. 